\title{
Fonem Deret Konsonan dalam Bahasa Indonesia
}

\author{
Ary Setyadi \\ Fakultas Ilmu Budaya, Universitas Diponegoro \\ mr.arysetyadi@gmail.com
}

\begin{abstract}
The existence of consonant series phonemes in Indonesian phonological learning is important, but strangely it has not received special attention, so it is interesting to be the object of study. Based on existing data, if we find a phoneme study of consonant series from several references, it turns out that the discussion is only a part / sub-section of the subject matter of the study.

The application of theory is based on the linguistic theory of phonological branches, phonemic subcabang, because the study focuses on the phoneme of the consonant series itself and its ability to form consonant sequences. The implementation of the study starts at three strategic stages as in linguistic research in general, namely: 1 . the stage of providing data, 2. the stage of classification and analysis of data, and 3. the stage of preparing the report. The phoneme data of consonant series is more secondary, so the existence of references is a data source.

The results of the consonant phoneme data analysis almost apply to all consonant phonemes in Indonesian, including loan / absorption (foreign) phonemes. The basis for determining the consonant phoneme starts with: 1. a consonant series is a consonant series of two / or more phonemes in one word, but in different syllables; 2. consonant phoneme data departs from the kinds of vocabulary in Indonesian; and 3. that the question of syllable decapitation is based on decapitation of the word form (morphological), not on sound (phonological) elements. The types of vocabulary used as data include: 1) original Indonesian vocabulary; 2) loan / absorption vocabulary, especially from the process "received by adjustment"; and 3) the "new form" vocabulary.

Keywords: Phonology, phonemes, phonemes, consonants, consonant series.
\end{abstract}

\section{Intisari}

Keberadaan fonem deret konsonan dalam pembelajaran fonologi bahasa Indonesia bersifat penting, tetapi anehnya belum mendapat perhatian secara khusus, sehingga menarik dijadikan objek kajian. Berdasarkan data yang ada, seandainya dijumpainya kajian fonem deret konsonan dari beberapa referensi, ternyata bahasan yang ada hanya merupakan bagian/subbab dari pokok kajian.

Penerapan teori mendasarkan pada teori linguistik cabang fonologi, subcabang fonemik, sebab kajian berfokus pada fonem deret konsonan itu sendiri dan kemampuannya dalam membentuk deret konsonan. Adapun pelaksanaan kajian bertolak pada tiga tahapan strategis sebagaimana dalam penelitian linguistik pada umumnya, yaitu: 1. tahap penyediaan data, 2. tahap klasifikasi dan analisis data, dan 3. tahap penyusunan laporan. Data fonem deret konsonan lebih bersifat sekunder, sehingga keberadaan referensi yang ada merupakan sumber data.

Hasil analisis data fonem deret konsonan hampir berlaku pada semua fonem konsonan yang ada dalam bahasa Indonesia, termasuk fonem pinjaman/serapan (asing). 
Dasar penentuan fonem deret konsonan bertolak pada: 1. deret konsonan merupakan deret konsonan dua/atau lebih fonem dalam satu kata, tetapi dalam suku kata yang berbeda; 2 . data fonem deret konsonan bertolak dari macam kosakata yang ada dalam bahasa Indonesia; dan 3. bahwa persoalan pemenggalan suku kata mendasarkan pada pemenggalan dari unsur bentuk kata (morfologis), bukan mendasarkan pada unsur bunyi (fonologis). Adapun macam kosakata yang dijadikan data mencakup: 1) kosakata asli bahasa Indonesia; 2) kosakata hasil pinjaman/serapan, khususnya kosakata yang bertolak dari proses "diterima dengan penyesuaian"; dan 3) kosakata hasil "bentukan baru".

Kata Kunci: Fonologi, fonemik, fonem, konsonan, deret konsonan.

\section{Pendahuluan}

Keberadaan fonologi merupakan bagian dari cabang linguistik, sebab apa yang disebut linguistik mencakup cabang: fonologi, morfologi, sintaksis, dan semantik (Verhaar, 1977: 12-138). Adapun satuan pembelajaran fonologi mencakup dua subbidang, yaitu: fonetik dan fonemik. Materi fonetik (lebih) berpusat pada keberadaan alat ucap penghasil bunyi bahasa, sedang meteri fonemik (lebih) berpusat pada fonem sebagai satuan bunyi bahasa terkecil. Sebab apa yang disebut dengan fonetik adalah, "1. Ilmu yang menyelidiki penghasilan, penyampaian, dan penerimaan bunyi bahasa; ilmu interdisipliner linguistik dengan fisika, anatomi, dan psikologi; 2. Sistem bunyi suatu bahasa.”, sedangkan apa yang disebut fonemik adalah, "1. Sistem fonem suatu bahasa; 2. Prosedur untuk menentukan fonem suatu bahasa; penyelidikan mengenai sistem fonem suatu bahasa. " (Kridalaksana, 2001: 56; Bandingkan: Badudu, 2003: 113; Kamus Besar Bahasa Indonesia, 2001: 319).

Bertolak dari kedua sajian kutipan di atas, pengkajian permasalahan deret konsonan, berada pada subbidang fonemik. Sebab apa yang disebut deret konsonan bertumpu pada adanya fakta bergabungnya dua atau lebih fonem konsonan dalam (satu) kata dasar, bukan dalam (satu) kata jadian. Dengan demikian dalam (satu) kata dasar dijumpai adanya kemampuan dua atau lebih fonem konsonan yang berderet. Adapun pengertian fonem dapat dijelaskan, "Satuan bunyi terkecil yang mampu menunjukkan makna, ...” (Kridalaksana, 2001: 55-5; Kamus Besar Bahasa Indonesia, 2001: 319) sebagaimana yang dijelaskan juga oleh Badudu, bahwa apa yang disebut fonem merupakan satuan bunyi bahasa yang terkecil sebagai penanda arti (2003: 113) --; sedangkan macam fonem yang ada pada (semua) bahasa, khususnya bahasa Indonesia, mencakup: fonem vokal, fonem diftong, dan fonem konsonan (Soedjarwo, dkk.: 1985/1986: 49-63; Setyadi dan Djoko Wasisto, 2018: 32). 
Berdasarkan data yang ada bahwa persoalan jumlah kemampuan daya gabung fonem dalam kata, secara pasti dapat dikatakan banyak dijumpai pada fonem konsonan, sebab jumlah fonem konsonan lebih banyak jika dibanding dengan jumlah fonem vokal maupun terlebih fonem diftong. Jumlah fonem konsonan sebanyak 25 , jumlah fonem vokal 7, dan jumlah fonem diftong 3 (Setyadi, 2018: 33-41). Jumlah fonem konsonan relatif lebih banyak berlaku wajar, sebab apa yang disebut dengan fonem konsonan mampu mnerima fonem konsonan asing/pinjaman: /sy, kh/; sedangkan, baik fonem vokal maupun fonem diftong tidak ada yang berasal dari fonem asing/pinjaman.

Perlu dicatatkan di sini bahwa berdasarkan data yang ada, persoalan kemampuan daya gabung (dua atau lebih) fonem konsonan mencakup dua persoalan yaitu: 1. yang berkait dengan gugus (cluster), yaitu, "deretan dua konsonan atau lebih yang tergolong dalam dalam satu suku kata yang sama." (Alwi, dkk., 2000: 52-53), contoh fonem /pr/ pada kata praktik, /pl/ pada kata plastik; dan 2. yang berkait dengan kelompok kosonan; yaitu, "Apabila dua konsonan tersebut berada dalam dua silabel yang berbeda.", contoh: /str/ dalam kata strategi. (Chaer, 2009: 51).

Kedua persoalan yang dimaksud menampakkan persoalan yang berbeda, sehingga kedua persoalan tersebut menarik untuk dikaji. Contoh deret konsonan dalam kata dasar /n-d/ pada kata tan-da, /s-t/ pada kata plas-tik; contoh gugus konsonan: /pr/ pada kata prima, /sp/ pada kata spontan. Dengan demikian tampak jelas bahwa antara gugus konsonan dengan deret konsonan berbeda. Sebab dikatakan gugus konsonan jika masingmasing fonem konsonan berada suku kata/silabel dan tidak terpisah, sedang jika deret konsonan, kedua fonem konsonan yang dimaksud dalam satu suku kata yang terpisah.

Akibat keberadaan fonem konsonan lebih banyak dalam berkemampuan bergabung dalam kata yang membentuk deret konsonan, maka pokok kajian dalam artikel ini lebih berfokus pada persoalan deret fonem konsonan saja. Dengan demikian tujuan yang hendak dikaji adalah: mencari dan menentukan kemampuan fonem konsonan dalam membentuk deret konsonan. Tujuan tersebut belum mendapat perhatian oleh pakar dan/atau pemerhati bahasa Indonesia sebagaimana dapat dilihat pada beberapa sajian ringkasan sumber bacaan/referensi yang menyoal fonologi bahasa Indonesia. Seandainya dijumpainya permasalahan yang dimaksud, pembahasan hanya merupakan bagian (subbab) dari persoalan kajian fonologi bahasa Indonesia. Bukti bahwa persoalan fonem deret konsonan 
relatif belum dikaji secara khusus dapat dilihat rangkuman simpulan beberapa referensi berikut.

Sumber bacaan/referensi hasil laporan penelitian yang berjudul "Perbandingan Tata Bunyi Bahasa Indonesia dan Bahasa Jawa” (Soedjarwo, dkk., 1985/1986: 144-153), kajian deret konsonan hanya merupakan bagian dari pokok persoalan (hanya merupakan subbab saja). Sajian semacam berlaku wajar sebab keberadaan deret konsonan disandingkan dengan keberadaan gugus konsonan. Contoh deret konsonan misalnya: /p-t/ pada sapta, /n$\mathrm{d} /$ pada tanda, /m-p/ pada tampak.

Sumber bacaan/referensi yang berjudul Tata Bahasa Baku Bahasa Indonesia hanya menyinggung masalah gugus konsonan saja, sehingga persoalan deret konsonan sebagaimana yang dimaksud dalam artikel ini tidak mendapat perhatian sama sekali. Adapun pengertian gugus konsonan dalam sumber yang dimaksud dikatakan, "Deretan dua konsonan atau lebih tergolong dalam satu suku kata yang sama". Contoh: /pr/pada praktik (Moeliono (Ed.), 1988: 42).

Bertolak dari pengertian dan contoh di atas, tampak jelas bahwa apa yang disebut gugus konsonan, bahwa keberadaan dua atau lebih fonem yang bergabung berada pada satu suku (kata). Sajian bahasan hanya pada sebagaimana contoh /pr/ pada kata praktik, sedang yang berkait dengan deret fonem konsonan sebagaimana contoh /t-d/ pada kata tanda, /m-p/ pada kata tampak tidak dibicarakan.

Sumber lain yang juga berbentuk buku juga hanya menyoal gugus konsonan saja (sebagaimana telah disinggung di atas), sebagaimana pendapat Alwi, dkk. (2000: 52-53) dan (Chaer, 2009: 51). Masing sumber hanya memberikan contoh gugus konsonan: /pr/ pada kata plastik, /tr/ pada kata sastra; /str/ pada kata strategi.

Bersumber dari Kamus Linguistik (Kridalaksana, 2001: 70) hanya menyebut dan memberikan pengertian gugus atau cluster tanpa diberikan contoh data, dengan tanpa disandingkan dengan persoalan kelompok konsonan, yaitu dikatakan, "1. Urutan-urutan unsur bahasa seperti gugus konsonan, ...; 2. Linguistik areal. Kelompok dialek atau bahasa yang memiliki ciri-ciri yang bersamaan karena tempatnya berdekatan.”.

Bersumber dari buku berjudul Dasar-dasar Linguistik Umum (Kentjono (Ed.), 1982: 21-38), meskipun sajian bahasan telah menyinggu pembagian macam-macam fonem, dan juga persoalan fonotaktik (persukuan (kata)), tetapi persoalan gugus dan deret konsonan yang keberadaannya dalam kata tidak disinggung sama sekali. Sajian bahasan 
fonotaktik/suku kata hanya menyoal pola (struktur) internal kata. Yaitu hanya berfokus pada: bahwa apa yang disebut dengan bentuk kata, secara internal merupakan gabungan dari suku kata. Sajian bahasan semacam juga berlaku pada buku yang berjudul Fonetik dan Fonologi (Yusuf, 1998: 1-138); demikian yang ada dalam buku yang berjudul Fonetik (Marsono, 1986: 1-117).

Bersumber dari hasil laporan penelitian berjudul "Sifat Fungsional dan Manfaat Pasangan Minimal Fonem dalam Pembelajaran Fonologi Bahasa Indonesia" (Setyadi dan Djoko Wasisto, 2018: 1-50) juga tidak menyinggung persoalan gugus dan deret konsonan, meskipun dalam sajian bahasan secara mendalam telah disinggung macam dan jumlah fonem konsonan dalam bahasa Indonesia. Persoalan kajian lebih berfokus pada upaya pembuktian 'pasangan minimal' sebagai alat pembuktian adanya fonem yang bersifat fonemis, meskipun dalam contoh data saat dibuatkan pasangan dua kata yang kontras/beda makna berkait dengan persoalan pola struktur internal kata sebagaimana persoalan yang ada dalam kasus fonem deret konsonan. Dari data dijumpai juga adanya persoalan fonem deret konsonan, misalnya $/ \mathrm{n}-\mathrm{d} /$ dalam `pasangan minimal pandu x pandai, /n-t/ dalam ’pasangan minimal pintu x pinta.

\section{Metode Penelitian}

Metode (penelitian) yang diterapkan untuk analisis data berlaku sebagaimana penelitian linguistik pada umumnya, yaitu dengan bertolak pada tiga tahapan strategis: 1. tahap penyediaan/pengumpulan data, 2. tahap klasifikasi dan analisis data, dan 3. tahap penulisan/penyusunan laporan (Sudaryanto, 1983: 24-26).

Tahap penyediaan/pengumpulan data lebih bertolak pada data sekunder, yaitu dengan dimanfaatkannya keberadaan sumber bacaan yang membicarakan fonologi bahasa Indonesia. Sebab temuan data yang bersifat primer relatif tidak mudah. Sebab persoalan gugus/deret konsonan berkait pola struktur internal bentuk kata dasar, sehingga keberadaan Kamus Besar Bahasa Indonesia (2001). Temuan data kemudian dicatat dalam kartu data, sehingga teknik yang digunakan dalam penyediaan/pengumpulan data bertolak pada penerapan metode simak dengan teknik libat simak dan teknik pengartuan data pada kartu data.

Tahap klasifikasi data bertolak pada fakta pola struktur internal bentuk data (kata) yang ada, sehingga diperlukan metode pembagian unsur langsung atas dasar persukuan 
(kata). Sebab apa yang disebut bentuk kata merupakan gabungan fonem. Berdasarkan gabungan fonem yang ada, dimungkinkan adanya gabungan fonem konsonan yang berdasarkan sifat silabisnya berada pada suku yang terpisah. Contoh: /r-k/ pada kata murka, /s-t/ pada kata dusta. Tahap analisis data, sebagaimana telah disinggung di atas, bertolak pada penerapan teori linguistik bidang fonologi subbidang fonemik (dengan tanpa mengesampingkan subbidang fonetik). Alasan subbidang fonetik diperlukan, sebab analisis data atas gabungan fonem konsonan berkait dengan peran alat ucap. Contoh kata tanda terdiri atas suku kata tan dan $d a$, sehingga ditemukan gugus/deret konsonan /n-d/. Secara fonetik keberadaan fonen /n/ dan fonem /d/ sedaerah titik artikulasi, yatu sebagai fonem dental.

Tahap penulisan/penyusunan laporan merupakan tahap akhir, yaitu merupakan tahap setelah dapat dianalisisnya data yang ada, sehingga tahap ketiga ini merupakan tahap akhir (pelaksanaan) penelitian.

\section{Hasil dan Pembahasan}

Fokus bahasan dalam artikel ini (sebagaimana telah disinggung di depan) hanya mengkaji persolan deret konsonan saja, sedang persoalan gugus konsonan tidak dikaji meskipun berdasarkan data yang ada antara deret konsonan dengan gugus konsonan berada dalam satu suku kata dasar. Alasan mendasar mengapa hanya mengkaji deret konsonan, sebab persoalan antara deret konsonan dengan gugus konsonan itu berbeda. Kalau deret konsonan persoalan penggabungan dua atau lebih fonem konsonan berada pada suku yang berbeda dalam satu kata dasar, sedang kalau gugus (cluster) konsonan persoalan pernggabungan dua atau lebih fonem konsonan berada dalam satu kata. Adapun analisis data fonem deret konsonan mendasarkan pada:

Pertama, bahwa apa yang disebut dengan deret konsonan harus merupakan gabungan dua atau lebih fonem konsonan yang terletak dalam satu suku kata dalam kata dasar (sebagaimana pengertain deret konsonan di atas).

Kedua, temuan data bertolak dari macam kosakata bahasa Indonesia yang mencakup: 1. kosakata asli bahasa Indonesia, contoh: /k-t/ pada kata dasar sakti, /n-k/ pada kata dasar mungkin, /n-c/ pada kata dasar panci; 2. kosakata hasil pinjaman/serapan dari kata bahasa asing, khususnya yang melalui proses "diterima dengan penyesuaian", sedang yang melalui proses "diterima "apa adanya" tidak disinggung, sebab kosakata kata 
hasil pinjaman/serapan yang dimaksud, khususnya dari bahasa Inggris mudah dijumpainya persoalan deret konsonan. Contoh deret konsonan yang melalui proses "diterima dengan penyesuaian", contoh: /k-t/ pada kata dasar efektif, /n-s/ pada kata dasar sensitif, /p-t/ pada kata dasar eliptis; dan 3. Kosakata hasil "bentukan baru", contoh: /n-t/ pada kata dasar (kain) rentang, /n-g/ pada kata dasar tenggat, /n-g/ pada kata dasar canggih (Setyadi, 2010: $5-6)$.

Ketiga, persoalan penentuan pemenggalan suku kata berdasar pada penggalam morfologis (bentuk), bukan fonologis (bunyi) (Moeliono (Ed.), 1988: 93) . Contoh hasil penggalam kata april adalah ap-ril (atas dasar bentuk), bukan a-pril sebagai akibat hasil pemenggalan kata atas suku kata berdasarkan unsur bunyi. Contoh kata pamrih, hasil penggalan suku katanya adalah pam-rih, bukan pa-mrih.

Bertolak dari penyediaan data, klasifikasi dan analisis data, akhirnya dapat ditemukan fonem deret konsonan, yaitu:

1. fonem deret konsonan yang berawal fonem /p/ berderet dengan fonem: /t, r, s/ , contoh:

1) /p-t/: sapta, cipta, kapten

2) /p-r/: april, pamrih

3) /p-s/: opsir, kapsul, adopsi

Khusus contoh fonem deret konsonan pada kata april, secara ucapan memang berbunyi a-pril dan pa-mrih, tetapi secara (pe)menggalan suku katanya adalah ap-ril dan pamrih.

2. fonem deret konsonan yang berawal fonem /b/ berderet dengan fonem /d, j, s, t/, contoh:
1) /b-d/: abdi, sabda
2) /b-j/: abjad
3) /b-s/: absen, abstrak, absolut
4) /b-t/: sabtu

3. fonem deret konsonan yang berawal fonem $/ \mathrm{t} /$ berderet dengan fonem $/ \mathrm{m}, \mathrm{n}, \mathrm{s}, \mathrm{w} /$, contoh:
1) /t-m/: patma, atma
2) /t-n/: ratna
3) /t-s/: atsiri
4) t-w/: fatwa, satwa

4. fonem deret konsonan yang berawal fonem /d/ berderet dengan fonem /m, f, j/, contoh: 

1) /d-m/: administrasi
2) /d-f/: advertensi, adverbial, adven
3) /d-j/: adjektif

5. fonem deret konsonan yang awal fonem /k/ berderet dengan fonem /b, t, d, m, n, s, y, w/, contoh:

1) /k-b/: akbar, takbir, sakban

2) k-t/: bakti, sakti, fakta

3) /k-d/: takdir, bakdat

4) /k-m/: makmur, sukma, bakmi

5) /k-n/: makna, laknat, oknum

6) /k-s/: paksa, maksud, taksi

7) /k-y/: rakyat, rukyat

8) /k-w/: dakwa, dakwah, bakwan

6. fonem deret konsonan yang berawal fonem /g/ berderet dengan fonem /m, s/, contoh:

1) magma, sigma, dogma

2) tagsa

7. fonem deret konsonan yang berawal fonem $/ \mathrm{m} /$ berderet dengan fonem $/ \mathrm{p}, \mathrm{b}, \mathrm{d}, \mathrm{s}, \mathrm{r}, \mathrm{z} /$, contoh:
1) /m-p/: sampan, lampau, gampang
2) /m-b/: lambang, bambu, kambing
3) /m-d/: lamda
4) /m-s/: imsak, amsal
5) /m-r/: lumrah
6) /m-z/: hamza

8. fonem deret konsonan yang berawal fonem /n/ berderet dengan fonem /p, t, d, c, j, s/, contoh:
1) /n-p/: tanpa
2) n-t/: runtuh, panti, gantung
3) /n-d/: panda, tindas, gandah
4) /n-c/: incar, goncang, kancing
5) /n-j/: pinjam, senja, panji
6) /n-s/: nuansa, ransel, insaf 
9. fonem deret konsonan yang berawal fonem / $/ \mathrm{h}$ berderet dengan fonem $/ \mathrm{p}, \mathrm{k}, \mathrm{g}, \mathrm{s} /$, contoh:

1) /n-p/: pingpong, sangsi

2) /n-k/: singkat, pangkat, blangko

3) /n-g/: anggun, sanggup, langgam

4) /n-s/: rangsang, pingsan, bangsa

10. fonem deret konsonan yang berawal fonem /f/ berderet dengan fonem /d, k, s, h/, contoh:
1) /f-d/: afdol
2) /f-k/: nafkah, afkir
3) /f-s/: tafsir, nafsu
4) /f-h/: mafhum

11. fonem deret konsonan yang berawal fonem /s/ berderet dengan fonem /p, b, t, d, k, g, c, $\mathrm{j}, \mathrm{m}, \mathrm{n}, \mathrm{h} /$, contoh:

1) /s-p/: aspal, aspek

2) /s-b/: tasbeh, asbes, asbak

3) /s-t/: sastra, mistik, master

4) /s-d/: masdar

5) /s-k/: riskan, basket, laskar

6) /s-g/: masgul

7) /s-c/: pasca

8) /s-j/: masjid

9) /s-m/: basmi, asma, kismis

10) /s-n/: bisnis, isnin

11) /s-h/: mahur

12. fonem deret konsonan yang berawal fonem $/ \mathrm{h} /$ berderet dengan fonem $/ \mathrm{t}, \mathrm{d}, \mathrm{k}, \int, \mathrm{l}, \mathrm{y}$, w/, contoh:

1) /h-t/: sejahtera, tahta, bahtera

2) /h-d/: syahdan, syahdu

3) /h-k/: bahkan, nahkoda

4) /h-f/: dahsyat

5) /h-1/: pahlawan 
6) /h-y/: wahyu

7) /h-w/: syahwat

13. fonem deret konsonan yang berawal fonem /l/ berderet dengan fonem /p. b, t, d, k, g, m,'s, h, y/, contoh:

1) /l-p/: alpa, kalpa

2) /l-b/: alba, jilbab

3) /l-t/: salto, halte

4) /l-d/: saldo

5) /l-k/: balkon

6) /l-g/: bulgur

7) /1-m/: halma, palma, salmon

8) /1-s/: silsilah, palsu, balsem

9) /l-h/: alhasil

10) /1-y/: bilyart, milyart, milyun

14. fonem deret konsonan yang berawal fonem /r/ berderet dengan fonem /p, b, t, d, k, g, $\mathrm{c} /, \mathrm{j}, \mathrm{m}, \mathrm{n}, \mathrm{s}, \mathrm{f}, \mathrm{h}, \mathrm{l}, \mathrm{y}, \mathrm{w} /$, contoh:

1) /r-p/: harpa

2) /r-b/: terbit, serbu, terbang

3) /r-t/: harta, kartu, kertas

4) /r-d/: merdu, serdadu, sarden

5) /r-k/: sirkus, terka, markas

6) /r-g/: surga, sergap, argumen

7) /r-c/: arca, percaya, percuma

8) /r-j/: sarjana, kerja, durjana

9) /r-m/: kurma, karma, permata

10) /r-n/: sirna, purno

11) /r-s/: sirsat, kursi, bersih

12) /r- $\int /$ : alirsyat

13) /r-h/: dirham, gerhana

14) /r-1/: perlu, perlente, perlak

15) /r-y/: karya, surya

16) /r-w/: tarwih, perwira, arwah 


\section{Simpulan}

Berdasarkan sajian hasil kajian temuan fonem deret konsonan di atas, akhirnya dapat dikedepankan simpulan:

Keberadaan fonem deret konsonan dalam pembelajaran fonologi bahasa Indonesia perlu mendapat perhatian secara khusus, sebab berkait dengan: persoalan macam fonem dan kemampuan daya gabung fonem konsonan dalam membentuk deret konsonan, dan persoalan fonem deret konsonan sebenarnya tidak hanya berkait dengan bidang fonologi subbidang fonemik saja, tetapi juga berkait dengan subbidang fonetik. Akibat persoalan fonem deret konsonan berbeda dengan fonem gugus konsonan, maka keberadaan fonem gugus konsonan perlu juga dikaji juga, sebab hasil akhir kajian fonem gugus konsonan akan melengkapi kajian fonem deret konsonan.

\section{Daftar Pustaka}

Alwi, Hasan, dkk.. 2000. Tata Bahasa Baku Bahasa Indonesia. Jakarta: Pusat Bahasa dan Balai Pustaka.

Badudu. J.S. Kamus Kata-kata Serapan Asing dalam Bahasa Indonesia. Jakarta: Buku Kompas.

Chaer, Abdul. 2009. Fonologi Bahasa Indonesia. Jakarta: Rineka Cipta.

Kamus Besar Bahasa Indonesia. 2001. Jakarta: Balai Pustaka

Kentjono, Djoko (Ed.). 1982. Dasar-dasar Linguistik Umum. Jakarta: Fak Sastra UI.

Kridalaksana, Harimurti. 2001. Kamus Linguistik. Jakarta: Gramedia Pustaka Utama.

Marsono. 1986. Fonetik. Yogyakarta: Kanisius.

Moeliono, Anton M (Ed,), dkk. 1988. Tata Bahasa Baku Bahasa Indonesia. Jakarta: Balai Pustaka.

Setyadi, Ary. 2010. "Bahasa Indonesia dalam Karya Ilmiah”. Hanbook. Fak. Sastra Undip, Semarang.

Setyadi, Ary dan Djoko Wasisto. 2018. "Sifat Fungsional dan Manfaat 'Pasangan Minimal Fonem dalam Pembelajaran Fonologi Bahasa Indonesia”. Laporan Penelitian. Fak. Ilmu Budaya Undip, Semarang.

Soedjarwo, dkk. 1985/1986. "Perbandingan Tata Bunyi Bahasa Indonesia dan Bahasa Jawa". Laporan Penelitian. Projek Penelitian Bahasa dan Sastra Indonesia dan Daerah Propinsi Jawa Tengan, Departemen Pendidikan, Semarang.

Sudaryanto. 1983, Metode dan Aneka Teknik Analisis Bahasa: Pengantar Penelitian Wahana Kebudayaan secara Linguistik. Yogyakarta: Duta Wacana University Press. 
Yusuf, Suhendra. 1988. "Fonetik dan Fonologi. Jakarta: PT Gramadia Pustaka Utama. Verhaar, WJ. 1977. Pengantar Linguistik. Yogyakarta: Gadjah Mada University Press. 